2013-12-15

Novel insights into pancreatic -cell glucolipotoxicity from real-time functional analysis of mitochondrial energy metabolism in INS-1E insulinoma cells.

\title{
Barlow, J
}

http://hdl.handle.net/10026.1/3057

10.1042/BJ20131002

Biochem J

Portland Press Ltd.

All content in PEARL is protected by copyright law. Author manuscripts are made available in accordance with publisher policies. Please cite only the published version using the details provided on the item record or document. In the absence of an open licence (e.g. Creative Commons), permissions for further reuse of content should be sought from the publisher or author. 
Novel insights in pancreatic beta cell glucolipotoxicity from real-time functional analysis of mitochondrial energy metabolism in INS-1E insulinoma cells

Jonathan Barlow ${ }^{1}$ and Charles Affourtit ${ }^{1,2}$

${ }^{1}$ School of Biomedical and Healthcare Sciences, Plymouth University, Drake Circus, Plymouth PL4 8AA, UK

${ }^{2}$ Address correspondence to charles.affourtit@plymouth.ac.uk

\section{Page Heading}

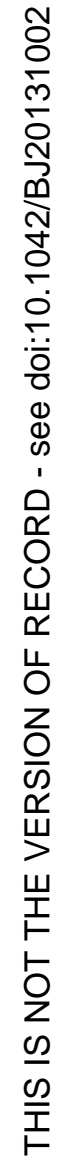

Pancreatic beta cell glucolipotoxicity and mitochondrial dysfunction 


\begin{abstract}
High circulating glucose and free fatty acid levels can cause pancreatic beta cell failure. The molecular mechanisms of this beta cell glucolipotoxicity are yet to be established conclusively. Here we report on the involvement of mitochondrial dysfunction in fatty acidinduced beta cell failure. We have used state-of-the-art extracellular flux technology to functionally probe mitochondrial energy metabolism in intact INS-1E insulinoma cells in real-time. We show that 24-hr palmitate exposure at high glucose attenuates the glucosesensitivity of mitochondrial respiration and lowers coupling efficiency of glucose-stimulated oxidative phosphorylation. These mitochondrial defects coincide with an increased level of reactive oxygen species (ROS), impaired glucose-stimulated insulin secretion (GSIS) and decreased cell viability. Palmitate lowers absolute glucose-stimulated respiration coupled to ATP synthesis, but does not affect mitochondrial proton leak. Palmitate is not toxic when administered at low glucose unless fatty acid beta oxidation is inhibited. Palmitoleate, on the other hand, does not affect mitochondrial respiration, ROS levels, GSIS or cell viability. Whilst palmitoleate protects against the palmitate-induced ROS increase and cell viability loss, it does not protect against respiratory and insulin secretory defects. We conclude that mitochondrial dysfunction contributes to fatty acid-induced GSIS impairment, and that glucolipotoxic cell viability and GSIS phenotypes are mechanistically distinct.
\end{abstract}

\title{
Keywords
}

pancreatic beta cell glucolipotoxicity, glucose-stimulated insulin secretion, mitochondrial dysfunction, oxidative phosphorylation, reactive oxygen species, type 2 diabetes

\section{Summary Statement}

Obesity-related pancreatic beta cell failure contributes to development of type 2 diabetes. We show that defects in mitochondrial oxidative phosphorylation largely account for fatty acidinduced impairment of glucose-stimulated insulin secretion, but not for the lipotoxicityrelated loss of beta cell viability.

\footnotetext{
\#Abbreviations

CPT-1, carnitine palmitoyltransferase-1; FBS, fetal bovine serum; GSIS, glucose-stimulated insulin secretion; HEPES, 4-(2-hydroxyethyl)-1-piperazineethanesulfonic acid; MitoSOX, mitochondria-targeted hydroethidine; NEFA, non-esterified fatty acid; ROS, reactive oxygen species; UCP2, uncoupling protein-2
} 


\section{INTRODUCTION}

The risk of developing type 2 diabetes is greatly increased in obese individuals [1] and a major mediator of this risk is a chronic elevation of circulating non-esterified fatty acids $\left(\mathrm{NEFAs}^{\#}\right)$ [2]. It is generally accepted that there is a causal relationship between chronically high NEFA levels and pancreatic beta cell failure. This pathological link, which is often referred to as 'beta cell lipotoxicity' [3], is responsible for the impaired insulin secretion that contributes to the development of obesity-related hyperglycaemia [4].

The precise mechanisms by which NEFAs lead to beta cell failure are subject of ongoing debate, which is partly due to the relatively complicated nature of lipotoxicity $[5,6]$. Exposure time, for example, is a critical factor that determines whether or not a particular fatty acid will be detrimental (long exposure) for beta cell performance or in fact beneficial (short exposure). It is worth stressing in this respect that the exposure necessary for toxic effects is poorly defined and varies dramatically between experimental systems ranging from a few hours in cultured cell models to many years in human subjects [5]. Moreover, not all fatty acids are equal as it has been reported that the toxic effect of NEFAs on beta cells depends on carbon chain length and double bond configuration [7]. Long-chain saturated NEFAs such as palmitate are generally harmful to beta cells, whereas unsatured molecules such as palmitoleate are relatively well tolerated and may even protect against the adverse effects of their saturated equivalents [7]. Importantly, even chronic exposure to high levels of saturated NEFAs is not necessarily harmful to beta cells, as toxicity often depends on a high glucose level - given this glucose permissibility, lipotoxicity is more correctly referred to as 'glucolipotoxicity' [8].

Glucolipotoxicity is an umbrella term that covers the combined deleterious effects of supraphysiological glucose and NEFA levels on both the viability and function of pancreatic beta cells [5]. Cellular defects that may be responsible for NEFA-induced beta cell death [9] or loss of insulin secretory function [10], are in abundance: glucolipotoxicity has for example been associated with regulatory gene transcription changes [11], epigenetic alterations [12], inflammation [13], defected cell signalling [14], oxidative stress [15], endoplasmic reticulum stress [16], and with mitochondrial dysfunction [17]. However, the relative importance of these multifarious NEFA effects and, indeed, their causal relations are unclear at present. Some important mechanistic questions are yet to be answered too. For example, anabolic derivatives, which likely emerge from the glycerolipid/free fatty acid cycle [18], are widely held responsible for the detrimental effects of fatty acids, but the nature of such derivatives remains elusive [5]. The mechanism by which unsaturated NEFAs offer cytoprotection against the harmful effects of their saturated equivalents remains equally obscure [19] and, although such protection prevents cellular death [7], it is unclear if it equally applies to the many other glucolipotoxic effects.

Following the observation that mitochondrial uncoupling protein-2 (UCP2) dampens glucose-stimulated insulin secretion (GSIS) in mouse islets [20], mitochondrial dysfunction has been linked causally to beta cell glucolipotoxicity and development of type 2 diabetes [17]. However, the GSIS improvement observed in mice after global UCP2 knockout on a mixed genetic background [20] is fully lost when the protein is knocked out on congenic backgrounds [21]. Instead, genetically pure mice exhibit impaired GSIS, which has been attributed to the persistent oxidative stress such animals face [21]. Given these results, the UCP2 upregulation observed under glucolipotoxic conditions was interpreted as a stress response preventing fuel-induced oxidative damage [15], probably by allowing proton leak across the mitochondrial inner membrane [22,23]. Recent studies with pancreatic islets isolated from beta cell-specific UCP2 knockout mice [24] and INS-1E insulinoma cells [23] show that UCP2 attenuates GSIS and lowers reactive oxygen species (ROS) levels. These 
findings are consistent with a dual role for UCP2 in GSIS regulation and oxidative stress protection. Whilst the UCP2 role in glucolipotoxicity is yet to be established firmly [5], it is likely that other defects in mitochondrial function contribute to the harmful NEFA effects on beta cell function and viability [25]. When possible mitochondrial dysfunction is explored in cells [26], it is generally important to define explicitly which aspects of mitochondrial physiology are important for the specific function of a given cell. In pancreatic beta cells, glucose-sensitivity of respiration and the coupling between respiration and ATP synthesis are two features of mitochondrial function that are essential for triggering GSIS (Fig. 1A, [27]). Furthermore, ROS that are involved in non-canonical GSIS [28] are at least partly mitochondria-derived [23].

In the study reported here, we have exploited extracellular flux technology to probe mitochondrial function in INS-1E insulinoma cells [29] that were exposed to glucolipotoxic conditions that cause loss of cell viability and GSIS impairment. By comparing the effects of palmitate and its monounsaturated counterpart palmitoleate on basal mitochondrial respiration and both glucose-sensitivity and coupling efficiency of oxidative phosphorylation we show that (i) mitochondrial dysfunction contributes significantly to palmitate-induced GSIS defects, (ii) palmitate-provoked viability and GSIS phenotypes are mechanistically distinct, (iii) proton leak does not contribute to palmitate-induced mitochondrial dysfunction, and (iv) fatty acid beta oxidation restricts palmitate-induced mitochondrial dysfunction.

\section{EXPERIMENTAL}

\section{Cell Culture}

INS-1E insulinoma cells were maintained in RPMI-1640 medium containing $11 \mathrm{mM}$ glucose, $5 \%(\mathrm{v} / \mathrm{v})$ fetal bovine serum (FBS), $10 \mathrm{mM}$ 4-(2-hydroxyethyl)-1-piperazineethanesulfonic acid (HEPES), $1 \mathrm{mM}$ sodium pyruvate, $50 \mathrm{U} / \mathrm{mL}$ penicillin, $50 \mu \mathrm{g} / \mathrm{mL}$ streptomycin, $500 \mu \mathrm{M}$ $\beta$-mercaptoethanol and $2 \mathrm{mM}$ L-glutamine [30]. Cells were seeded at 60,000 cells/well and, at $70-80 \%$ confluence, exposed to NEFAs for $24 \mathrm{hr}$ in serum-free RPMI containing 4 or 11 $\mathrm{mM}$ glucose. NEFA exposure at low glucose was executed $\pm 50 \mu \mathrm{M}$ etomoxir. NEFAs were conjugated to bovine serum albumin (BSA), so control cells were exposed to BSA alone.

\section{NEFA-BSA conjugation}

Fatty acid-free BSA (Sigma A7030) was dissolved at $1.6 \mathrm{mM}$ in medium containing $135 \mathrm{mM}$ $\mathrm{NaCl}, 3.6 \mathrm{mM} \mathrm{KCl}, 10 \mathrm{mM}$ HEPES (pH 7.4), and $0.5 \mathrm{mM} \mathrm{MgCl}_{2}$. Palmitate $(8 \mathrm{mM})$, palmitoleate $(3.5 \mathrm{mM})$ or a combination of palmitate $(5.5 \mathrm{mM})$ and palmitatoleate $(1 \mathrm{mM})$ were added as powder or liquid, respectively, and stirred continuously at $35-38{ }^{\circ} \mathrm{C}$ for $1 \mathrm{hr}$ or until all NEFAs had dissolved. Cooled BSA:NEFA conjugations were filter-sterilised and stored at $4{ }^{\circ} \mathrm{C}$. When added to cultures, BSA:NEFA mixtures were diluted 40x. The applied BSA and NEFA concentrations were chosen because of published binding parameters [31] that predict the respective molar ratios should result in similar total unbound NEFA levels.

\section{Insulin secretion}

Cells were seeded and exposed to NEFAs on 96-well culture plates and then starved for $2 \mathrm{~h}$ in RPMI lacking glucose and sodium pyruvate, and containing 1\% (v/v) FBS. Cells were then washed with glucose-free Krebs-Ringer medium (KRH) comprising $135 \mathrm{mM} \mathrm{NaCl}, 3.6 \mathrm{mM}$ $\mathrm{KCl}, 10 \mathrm{mM}$ HEPES ( $\mathrm{pH} 7.4$ ), $0.5 \mathrm{mM} \mathrm{MgCl} 2,1.5 \mathrm{mM} \mathrm{CaCl}_{2}, 0.5 \mathrm{mM} \mathrm{NaH} \mathrm{PO}_{4}, 2 \mathrm{mM}$ glutamine, and $0.1 \%(\mathrm{w} / \mathrm{v}) \mathrm{BSA}$ and incubated in this medium for $30 \mathrm{~min}$ at $37{ }^{\circ} \mathrm{C}$ on a shaking plate incubator (Labnet International, Oakham, UK) set at $100 \mathrm{rpm}$. Next, glucose- 
free KRH was replaced with $\mathrm{KRH}$ containing $0-28 \mathrm{mM}$ glucose or $4 \mathrm{mM}$ glucose and $50 \mathrm{mM}$ $\mathrm{KCl}$. After another $30 \mathrm{~min}$ incubation, supernatants were collected, centrifuged to pellet any detached cells, and assayed for insulin by ELISA (Mercodia, Uppsala, Sweden) using mouse insulin as standard.

\section{Mitochondrial bioenergetics}

Mitochondrial function was measured in intact attached INS-1E cells as described before [29]. Cells seeded and NEFA-exposed on XF24 culture plates (Seahorse Bioscience) were washed in glucose-free KRH lacking BSA and incubated in this medium for $30 \mathrm{~min}$ at $37^{\circ} \mathrm{C}$ under air. Plates were transferred to a Seahorse XF24 extracellular flux analyser (controlled at $37{ }^{\circ} \mathrm{C}$ ) for a 10-min calibration and 4 measurement cycles to record basal cellular respiration (Figs $1 \mathrm{~B}$ and $1 \mathrm{C}$ ). Up to $28 \mathrm{mM}$ glucose was then added to stimulate respiration and, subsequently, $5 \mu \mathrm{g} / \mathrm{mL}$ oligomycin and a mixture of $1 \mu \mathrm{M}$ rotenone plus $2 \mu \mathrm{M}$ antimycin $\mathrm{A}$ were added to, respectively, inhibit the ATP synthase and to determine non-mitochondrial respiration.

\section{Mitochondrial ROS}

ROS levels were estimated from MitoSOX oxidation rates as described previously [23,32]. Cells seeded and NEFA-exposed on 96-well plates were washed in glucose-free KRH lacking $\mathrm{BSA}$, incubated in this medium for $30 \mathrm{~min}$ at $37^{\circ} \mathrm{C}$ under air, and were then transferred to a multimode plate reader (PHERAstar FS BMG LABTECH). Following injection of $5 \mu \mathrm{M}$ MitoSOX (Invitrogen M36008), fluorescence was monitored at 28-sec intervals for $30 \mathrm{~min}$. The fluorescent MitoSOX oxidation products were excited at $510 \mathrm{~nm}$ and light emission was detected at $580 \mathrm{~nm}$. The plate reader's focal height was set at $3.4 \mathrm{~mm}$ and its gain was fixed between different experiments.

\section{Cell density}

Cell densities were determined to quantify NEFA effects on cell viability and to normalise data. For both purposes, the metabolic activity of INS-1E cells was probed on Seahorse XF24 plates by adding $50 \mathrm{nM} \mathrm{C}_{12}$-resazurin in $100 \mu \mathrm{L}$ RPMI to each well [32]. Shielded from light, the plate was then incubated for $50 \mathrm{~min}$ at $37^{\circ} \mathrm{C} / 5 \% \mathrm{CO}_{2}$. Metabolically active cells reduce $\mathrm{C}_{12}$-resazurin to the fluorescent $\mathrm{C}_{12}$-resorufin $\left(\lambda_{\mathrm{ex} / \mathrm{em}}=540 / 590 \mathrm{~nm}\right)$, which was detected using a PHERAstar FS plate reader (BMG LABTECH) in fluorescence intensity, bottomreading and well-scanning mode. For the normalisation of respiratory data (Figs 2A and 4), $\mathrm{KRH}$ was replaced with RPMI containing $\mathrm{C}_{12}$-resazurin immediately after measuring basal oxygen uptake, i.e., in the absence of any respiratory effectors. The respiratory activity in a particular well was normalised using the cell density measured in that same well [32]. MitoSOX oxidation data (Fig. 5) were normalised using averaged cell viabilities (Fig. 7).

\section{Statistical analysis}

Significance of mean differences was tested by ANOVA - applying Tukey's multiple comparison post-hoc analysis - using GraphPad Prism Version 6.0 for Mac OS X (GraphPad software, San Diego, CA, USA).

\section{RESULTS}

\section{Mitochondrial respiration}

When blood glucose rises, beta cells increase their oxidative catabolism of glucose, which leads to increased mitochondrial respiratory activity that is coupled to ATP synthesis (Fig. 
1A). In canonical GSIS, the glucose-induced increase in the ATP/ADP ratio is the key signal that triggers insulin release [33]. The typical respiratory trace shown in Fig. 1B illustrates that INS-1E cells indeed increase their oxygen uptake rate, by about $50 \%$, when subjected to 28 $\mathrm{mM}$ glucose. This cellular respiratory response to glucose is dampened to an approximately $25 \%$ increase (Fig. 1C) in cells that were exposed for $24 \mathrm{hr}$ to palmitate in the presence of 11 $\mathrm{mM}$ glucose. As expected, the oxygen consumption of control and palmitate-exposed cells is inhibited by both oligomycin and a mixture of rotenone and antimycin A (Figs 1B and 1C). The data shown in Figs $1 \mathrm{~B}$ and $1 \mathrm{C}$ are normalised to basal respiration measured in the absence of glucose. When corrected for non-mitochondrial oxygen uptake, which ranges from 0.5 to $0.6 \mathrm{fmol} \mathrm{O}_{2} / \mathrm{min} / \mathrm{cell}$ (Fig. 2A), the magnitude of this basal respiration is $2 \mathrm{fmol}$ $\mathrm{O}_{2} / \mathrm{min} /$ cell (Fig. 2A). Exposure to palmitate or palmitoleate, alone or combined, does not significantly affect either the basal mitochondrial or non-mitochondrial respiratory rates (Fig. 2A). However, at $11 \mathrm{mM}$ glucose, palmitate exposure lowers the glucose sensitivity of mitochondrial respiration (Fig. 2B). Basal mitochondrial oxygen consumption of control cells increases up to 2-fold when 4-28 mM glucose is administered, whereas oxygen consumption of palmitate-exposed cells increases maximally 1.2-fold. Similar exposure to palmitoleate does not affect glucose-sensitivity of INS-1E mitochondrial respiration, and palmitoleate does not provide significant protection against the desensitising effect of palmitate (Fig. 2B). When exposed at $4 \mathrm{mM}$ glucose, palmitate and palmitoleate, alone or combined, do not significantly affect the mitochondrial respiratory response to glucose (Fig. 1C). Probably due to differential glucose limitation, BSA control cells incubated at low glucose (Fig. 1C) tend to respond somewhat more strongly to glucose than cells exposed at high glucose (Fig. 1B).

\section{Coupling efficiency}

Coupling efficiency of oxidative phosphorylation is defined as the proportion of mitochondrial respiration linked to ATP synthesis [26]. Coupling efficiency can be approximated from the oligomycin-sensitivity of mitochondrial oxygen consumption [29] and may thus be derived from data as shown in Fig. 1. Because the inner membranes of INS-1E mitochondria allow an unusually high proton leak [34], INS-1E cells exhibit exceptionally low coupling efficiency $[22,23]$ as is reflected by Fig. 3A, which shows that control cells use just $50-55 \%$ of their glucose-stimulated mitochondrial respiratory activity to make ATP. Interestingly, palmitate exposure at high glucose lowers the coupling efficiency further, such that only $40 \%$ of the respiratory activity drives ATP synthesis at any applied glucose level (Fig. 3A). Palmitoleate exposure causes a small, statistically insignificant, rise in coupling efficiency (Fig. 3A). Mirroring the NEFA effects on the glucose-sensitivity of mitochondrial respiration (Fig. 2), palmitoleate does not protect against the negative effect of palmitate on coupling efficiency (Fig. 3A), and palmitate nor palmitoleate lower coupling efficiency when incubated at low glucose (Fig. 3B).

Coupling efficiency reflects all major processes underlying oxidative phosphorylation including substrate oxidation, ADP phosphorylation and proton leak across the mitochondrial inner membrane [29]. The detrimental palmitate effect at high glucose exposure on coupling efficiency (Fig. 3A) could, therefore, in principle be due to inhibitory effects on substrate oxidation and/or ADP phosphorylation, and/or to a stimulatory effect on proton leak. To distinguish between these possibilities, we calculated the absolute total glucose-stimulated respiratory activity (substrate oxidation) as well as absolute oligomycin-sensitive (ADP phosphorylation) and oligomycin-resistant (proton leak) activities. Fig. 4 shows that palmitate exposure causes statistically significant drops in both the total and the oligomycin-sensitive glucose-stimulated mitochondrial respiratory activities, indicating that ADP phosphorylationcoupled substrate oxidation has been compromised. Palmitoleate exposure lowers neither substrate oxidation nor ADP phosphorylation, but instead causes a small, statistically 
insignificant, stimulation of these processes (Fig. 4). Importantly, proton leak is not affected by exposure to palmitate and/or palmitoleate (Fig. 4).

\section{Mitochondrial ROS}

In addition to their textbook role in GSIS (Fig. 1A), mitochondria play an important part in less well understood, non-canonical GSIS mechanisms [35]. For example, ROS have been implicated as insulin secretion signals [28], and at least some of these ROS are mitochondriaderived [23]. To assess the effect of NEFAs on mitochondrial ROS, we probed MitoSOX oxidation in cells exposed to palmitate and palmitoleate, alone or in combination, at 11 or 4 $\mathrm{mM}$ glucose (Fig. 5). MitoSOX is a mitochondria-targeted hydroethidine analogue that is oxidised mainly by superoxide, but also by hydrogen peroxide [36]. The MitoSOX oxidation rate, calculated from fluorescence progress curves (Figs $5 \mathrm{~A}$ and $\mathrm{B}$ ), is thus proportional to mitochondrial ROS levels. The data shown in Fig. 5C reveal that palmitate exposure at 11 $\mathrm{mM}$ glucose causes a significant rise in ROS, whereas the equivalent palmitoleate exposure is without effect. Interestingly, palmitoleate dampens the palmitate-induced ROS increase (Fig. 5C). Palmitate nor palmitoleate stimulate ROS when cells are exposed at 4 instead of $11 \mathrm{mM}$ glucose. The mechanism by which palmitate increases mitochondrial ROS at high glucose is unclear at present. Pancreatic beta cells contain NADPH oxidases, however, that produce cytoplasmic superoxide [37], which is likely detected by MitoSOX that has not accumulated into the mitochondrial matrix [36]. Consistent with our data, the expression of a key NADPH oxidase component is increased by palmitate [38]. Irrespective of their origin, palmitoleate lowers palmitate-induced ROS significantly (Fig. 5C). This apparent palmitoleate protection against oxidative stress disconnects the effect of palmitate on ROS (Fig. 5) from its effects on oxidative phosphorylation (Figs 2-4).

\section{GSIS and cell viability}

To assess if the palmitate-induced defects in oxidative phosphorylation (Figs 2-4) and rise in ROS (Fig. 5) relate to any other lipotoxic effects, we measured insulin release (Fig. 6) and cell viability (Fig. 7). INS-1E insulin secretion is stimulated considerably by glucose, which is why this insulinoma cell line is widely used as beta cell model [30]. In our hands, basal INS-1E insulin secretion is more than doubled by high glucose and increased 1.6-fold by $\mathrm{KCl}$ (Fig. 6A). Although these responses are somewhat lower than those reported elsewhere [30], they nonetheless allow NEFA effects to be assessed. Palmitate exposure at $11 \mathrm{mM}$ glucose blunts both glucose- (Fig. 6B) and KCl-stimulated (Fig. 6C) insulin secretion completely, although the effect on $\mathrm{KCl}$-induced secretion appears not statistically significant. Palmitoleate exposure at high glucose, on the other hand, has no significant effect on GSIS (Fig. 6B) or KCl-induced insulin release (Fig. 6C). Importantly, the deleterious effects of palmitate on GSIS (Fig. 6B) and KCl-induced insulin secretion (Fig. 6C) are not prevented significantly by palmitoleate. This lack of protection mirrors the relative inconsequentiality of palmitoleate with respect to palmitate-induced defects in oxidative phosphorylation (Figs 2-4). Similar to the bioenergetic phenotypes, the lipotoxic GSIS effects also depend on the presence of a relatively high glucose level, since palmitate exposure at low glucose does not impair GSIS (Fig. 6D). Reminiscent of the mitochondrial respiratory response to glucose (Figs 1B, 1C), GSIS in BSA control cells is a little, but not significantly, higher at $4 \mathrm{mM}$ than at $11 \mathrm{mM}$ glucose (Figs 6D, 6B). Interestingly, palmitoleate exposure at low glucose, either alone or combined with palmitate, tends towards GSIS potentiation (Fig. 6D).

In line with the ROS, GSIS and mitochondrial respiratory effects, palmitate exposure at high glucose lowers cell viability (cell survival $<40 \%$ ), whereas palmitoleate is relatively harmless (Fig. 7A). Palmitate and/or palmitoleate do not cause statistically significant cell 
loss when administered at low glucose (Fig. 7B), which mirrors the glucose dependence of the ROS, GSIS and bioenergetic effects. Unlike the GSIS and bioenergetic phenotypes, palmitoleate protects against palmitate-induced cell loss at high glucose exposure (Fig. 7A). Such protection is indeed consistent with the prevention by palmitoleate of palmitate-induced ROS (Fig. 5C). NEFA effects on cell survival are also seen when viability is probed with nuclear instead of metabolic indicators (not shown).

\section{Mitochondrial palmitate toxicity at low glucose}

Palmitate only causes harm to INS-1E cells when administered at high glucose (Figs 2-3, 5-7). This exclusivity is likely explained by the Randle 'cycle' [39]: high glucose oxidation leads to accumulation of cytoplasmic malonyl-CoA, which inhibits carnitine palmitoyltransferase-1 (CPT1) thus preventing mitochondrial beta oxidation of fatty acids and promoting NEFA engagement in esterification-hydrolysis cycles [18] - this order of events is generally held responsible for the glucose permissibility of lipotoxicity [8]. To test if palmitate-induced effects on mitochondrial respiration would be enhanced when its breakdown were prevented, we exposed INS-1E cells to palmitate at low glucose in the presence of etomoxir, a specific CPT1 inhibitor [40] that inhibits acute palmitate oxidation by INS-1E cells [35]. Fig. 8A shows that 'BSA-etomoxir' control cells increase mitochondrial respiration about 2.2-fold in response to $28 \mathrm{mM}$ glucose. The equivalent response by 'palmitate-etomoxir' cells is just a 1.7-fold rise (Fig. 8A). Cells exposed to BSA at low glucose in the absence of etomoxir respond to $28 \mathrm{mM}$ glucose by increasing mitochondrial oxygen uptake roughly 2.5 -fold - this response is not affected by palmitate (Figs $8 \mathrm{~A}$ and $2 \mathrm{C}$ ). The respiratory response to $28 \mathrm{mM}$ glucose by cells exposed to BSA at high glucose, is lowered by palmitate from a 2-fold to a 1.2-fold stimulation (Figs 8A and 2B). Fig. 8A thus demonstrates that statistically significant palmitate toxicity arises at low glucose when NEFA catabolism is impeded. The emerging palmitate lipotoxicity on glucose-sensitivity of mitochondrial respiration becomes even more apparent when glucose responses are normalised to the respective BSA control responses (Fig. $8 \mathrm{~B})$. Interestingly, etomoxir's presence at low glucose exposure does not allow the palmitateinduced drop in coupling efficiency - assayed at $28 \mathrm{mM}$ glucose - that is seen at high glucose exposure (Fig. 8C, cf. Fig. 3). The limited mitochondrial dysfunction caused by palmitate at low glucose in the presence of etomoxir, suggests that palmitate inhibits glucose oxidation at multiple targets that have different affinities for palmitate or its toxic derivative(s).

\section{DISCUSSION}

\section{Mitochondrial dysfunction contributes to palmitate-induced GSIS defects}

Our functional bioenergetic analysis reveals that palmitate impairs aspects of mitochondrial function that underpin the insulin secretion ability of INS-1E cells: both glucose-sensitivity of mitochondrial respiration and coupling efficiency of oxidative phosphorylation are lowered (Figs 2B, 3A). Our results thus demonstrate that mitochondrial dysfunction contributes to the NEFA-induced GSIS defects reported by us (Fig. 6B) and others [10]. Agreeing with current concensus [5], the deleterious palmitate effects on mitochondrial function and GSIS depend on glucose (Figs 2C, 3B, 6D) and are, therefore, glucolipotoxic effects [8]. Functional insight in mitochondrial NEFA effects is scarce, but a recent study [12] associates palmitate-induced GSIS defects in INS-1 cells with (epi)genetic and metabolic changes, including diminished mitochondrial respiration. Consistent with our findings (Fig. 4), palmitate lowers glucosestimulated oxygen uptake coupled to phosphorylation, but does not affect proton leak [12]. Discrepant with our findings (Figs 2B, 3A), most likely because of experimental differences, palmitate does not seem to affect normalised glucose-sensitivity of mitochondrial respiration 
or coupling efficiency [12]. Palmitate exposure leads to a significantly increased ROS level (Fig. 5). Palmitate-induced ROS likely arise from cytoplasmic NADPH oxidase activity [38], although it remains of course possible that some or all of these ROS have a mitochondrial origin. Irrespective of where they arise, however, palmitate-induced ROS do almost certainly not contribute to impaired GSIS, because palmitoleate prevents the emergence of these ROS (Fig. 5C), whereas this unsaturated NEFA does not protect against palmitate-induced GSIS defects (Fig. 6B). Although our data demonstrate involvement of mitochondrial dysfunction in palmitate-induced GSIS impairment, palmitate also likely acts on non-mitochondrial processes relevant to GSIS, e.g. $\mathrm{K}_{\mathrm{ATP}}$ channel closure [41], $\mathrm{Ca}^{2+}$ channel opening [42] and exocytosis [43]. Attenuation of $\mathrm{KCl}$-induced insulin release by palmitate (Fig. 6C) agrees with such non-mitochondrial action.

This paper highlights the power of measuring beta cell oxidative phosphorylation in real-time, revealing that mitochondrial function reliably predicts GSIS. Our approach is curently limited to cells, which is unfortunate, as pancreatic islets arguably yield more insight in glucolipotoxic pathophysiology than insulinoma cells. Respirometry has been applied to islets [24,44], but it is hard to causally link islet bioenergetics, which are accounted for by many cell types, to insulin secretion, which is mediated by beta cells alone [35]. Methods need to be developed to distinguish between the contributions of all cell types to islet respiration before we can probe the physiological impact of our data in a meaningful way. Reassuringly, our previous INS-1E predictions - high proton leak [22] and a dual UCP2 role in GSIS regulation and oxidative stress protection [23] - have come true in islets $[15,24,44]$.

\section{Glucolipotoxic viability and GSIS phenotypes are mechanistically distinct}

Unlike palmitate, palmitoleate does not increase ROS (Fig. 5) and does not compromise oxidative phosphorylation, insulin secretion or cell viability (Figs 2B, 3A, 6B, 7A). Instead, palmitoleate protects against palmitate-induced cell loss (Fig. 7A), which mirrors published data [7,45], and prevents a palmitate-induced rise in ROS (Fig. 5). Importantly, palmitoleate does not ameliorate palmitate-induced defects in oxidative phosphorylation (Figs 2B, 3A) and GSIS (Fig. 6B). Such differential palmitoleate protection suggests that the glucolipotoxic viability and GSIS phenotypes are mechanistically distinct: whereas blunted mitochondrial glucose-sensitivity and coupling efficiency at least partly account for GSIS impairment, these defects unlikely cause cell viability loss. NEFA-induced apotosis might result from other mitochondrial dysfunction [46], perhaps involving ROS (Fig. 5). Our results thus support the idea that the many and varied glucolipotoxic manifestations are not explained by one unifying mechanism [5] - the data also shed light on causal interrelations between the multifarious palmitate effects.

Some structural aspects critical to the cytoprotective properties of unsaturated NEFAs are known, and protection may involve endoplasmic reticulum stress responses, G-proteincoupled receptors and NEFA esterification. Despite this knowledge, which has been reviewed expertly by others [6,7], the mechanism of cytoprotection remains elusive. Our data exclude mitochondrial oxidative phosphorylation from any mechanistic model, and thus weaken the reported idea [19] that unsaturated NEFAs enhance the clearance of saturated species by increasing beta oxidation. Moreover, our findings suggest that unsaturated NEFAs may indeed save beta cells from glucolipotoxic death, but they do not prevent functional deterioration of the surviving cells.

\section{Mechanism of palmitate-induced mitochondrial dysfunction}

UCP2 has been implicated in beta cell failure and development of type 2 diabetes [17], but its glucolipotoxic role is contentious [5]. Palmitate effects on glucose-sensitivity of respiration, 
coupling efficiency, and GSIS (Figs 2B, 3A, 6B) closely mirror UCP2 effects on INS-1E cells reported before [23]. However, our results demonstrate that palmitate exposure does not affect mitochondrial proton leak (Fig. 4). This important observation most likely rules out UCP2 involvement in the mitochondrial dysfunction reported here, since UCP2 contributes considerably to proton leak of INS-1E cells $[22,23]$. Related, possible palmitate stimulation of UCP2 expression and/or activity is expected to increase overall mitochondrial respiration $[22,23,47]$, which appears not the case (Fig. 2A). It remains unclear how palmitate exposure impedes glucose-fuelled oxidative phosphorylation, but multiple targets are likely [48].

\section{Fatty acid beta oxidation restricts palmitate-induced mitochondrial dysfunction}

Palmitate blunts the mitochondrial respiratory response to glucose when administered at low glucose in the presence of etomoxir (Figs 8A, 8B). Such etomoxir-induced palmitate toxicity agrees with the widely accepted notion that malonyl CoA accumulation accounts for glucose permissibility of lipotoxicity [8]. Our observation predicts that NEFA toxicity at high glucose may be ameliorated by stimulating beta oxidation (Fig. 9), which would lower the chance that toxic NEFA derivatives emerge from esterification-hydrolysis cycles [18]. The stimulatory effect of palmitoleate - a relatively harmless NEFA - on absolute mitochondrial respiration (Fig. 4) supports this prediction, although the effect is statistically not significant. The relative ease, compared to their saturated counterparts, by which unsaturated NEFAs are anabolised to stable triglyceride [49] and thus removed from esterification-hydrolysis cycles, further explains the harmless nature of palmitoleate. Promotion of palmitate oxidation [19] and triglyceride formation [49] have both been suggested to explain the protective effect of unsaturated NEFAs against palmitate toxicity, but lack of palmitoleate protection against mitochondrial respiratory defects (Figs 2B, 3A, 4) weakens the 'protection through oxidation' model.

We hypothesise that harmful NEFA effects could be outweighed by beneficial effects that are triggered by NEFAs per se or by their catabolites (Fig. 9), and that the experimental phenotype of any NEFA exposure reflects the balance of these harmful and beneficial effects. Palmitate for example, acutely benefits beta cell function by potentiating GSIS [50] - we suggest that such potentiation is not seen after sustained exposure because palmitate toxicity dominates the phenotype time-dependently. This metabolic balance model explains why 24$\mathrm{hr}$ palmitate exposure impairs GSIS at high glucose and is inconsequential at low glucose and, at the same time, why palmitoleate is inconsequential at high glucose and in fact potentiates GSIS at low glucose even after 24-hr exposure (Figs 6B, 6D). We suggest that beneficial and deleterious NEFA processes are not necessarily separated in time, but may coincide.

\section{Conclusion}

Cellular bioenergetics yield powerful insight in pancreatic beta cell function as mitochondrial activity appears a reliable GSIS predictor. Our data have provided new information on some of the causal interrelations between the multifarious glucolipotoxicity phenotypes. However, the data also underscore the complicated nature of NEFA toxicity, suggesting many targets for even the damaging effect of palmitate on glucose oxidation alone. The occurrence of multiple targets hampers the development of drugs to manage NEFA-induced beta cell failure, but our findings suggest an alternative: as glucolipotoxicity may be ameliorated by promoting mitochondrial beta oxidation, stimulating such oxidation, perhaps via controlled uncoupling, may prove an attractive therapeutic possibility. 


\section{AUTHOR CONTRIBUTION}

CA conceived and developed the project idea, JB and CA designed all experiments, JB executed and analysed all experiments, JB and CA wrote the paper.

\section{ACKNOWLEDGEMENT}

We thank Prof. Noel Morgan (Exeter University Medical School, UK) for the kind donation of INS-1E insulinoma cells and his general enthusiasm for the project.

\section{FUNDING}

Work in our lab is supported by the Medical Research Council [New Investigator Research Grant G1100165 to CA] and Plymouth University [PhD studentship to JB].

\section{REFERENCES}

1. Garber, A. J. (2012) Obesity and type 2 diabetes: which patients are at risk? Diabet Obes Met 14, 399-408

2. Muoio, D. M. and Newgard, C. B. (2008) Mechanisms of disease: Molecular and metabolic mechanisms of insulin resistance and $\beta$-cell failure in type 2 diabetes. Nat Rev Mol Cell Biol 9, 193-205

3. Unger, R. H. (1995) Lipotoxicity in the pathogenesis of obesity-dependent NIDDM. Genetic and clinical implications. Diabetes 44, 863-870

4. Prentki, M. and Nolan, C. J. (2006) Islet beta cell failure in type 2 diabetes. J Clin Invest 116, 1802-1812

5. Poitout, V., Amyot, J., Semache, M., Zarrouki, B., Hagman, D. and Fontés, G. (2010) Glucolipotoxicity of the pancreatic beta cell. Biochim Biophys Acta 1801, 289-298

6. Newsholme, P., Keane, D., Welters, H. J. and Morgan, N. G. (2007) Life and death decisions of the pancreatic $\beta$-cell: the role of fatty acids. Clin Sci 112, 27-42

7. Morgan, N. G. and Dhayal, S. (2010) Unsaturated fatty acids as cytoprotective agents in the pancreatic $\beta$-cell. Prostaglandins Leukotrienes \& Essential Fatty Acids 82, 231-236

8. Prentki, M., Joly, E., El-Assaad, W. and Roduit, R. (2002) Malonyl-CoA signaling, lipid partitioning, and glucolipotoxicity: role in beta-cell adaptation and failure in the etiology of diabetes. Diabetes 51, S405-S413

9. Lee, M.-S., Kim, K.-A. and Kim, H. S. (2012) Role of pancreatic $\beta$-cell death and cell death-associated inflammation in diabetes. Curr Mol Med 12, 1297-1310

10. Elks, M. L. (1993) Chronic perifusion of rat islets with palmitate suppresses glucosestimulated insulin release. Endocrinology 133, 208-214

11. Lovis, P., Roggli, E., Laybutt, D. R., Gattesco, S., Yang, J.-Y., Widmann, C., Abderrahmani, A. and Regazzi, R. (2008) Alterations in microRNA expression contribute to fatty acid-induced pancreatic beta-cell dysfunction. Diabetes 57, 27282736

12. Malmgren, S., Spegel, P., Danielsson, A. P., Nagorny, C. L., Andersson, L. E., Nitert, M. D., Ridderstråle, M., Mulder, H. and Ling, C. (2013) Coordinate changes in histone modifications, mRNA levels and metabolite profiles in clonal INS-1 832/13 beta cells accompany functional adaptations to lipotoxicity. doi: 10.1074/jbc.M112.422527

13. Akash, M. S. H., Rehman, K. and Chen, S. (2013) Role of inflammatory mechanisms in pathogenesis of type 2 diabetes mellitus. J Cell Biochem 114, 525-531

14. Haber, E. P., Hirabara, S. M., Gomes, A. D., Curi, R., Carpinelli, A. R. and Carvalho, C. 
R. O. (2003) Palmitate modulates the early steps of insulin signalling pathway in pancreatic islets. FEBS Lett 544, 185-188

15. Pi, J. and Collins, S. (2010) Reactive oxygen species and uncoupling protein 2 in pancreatic $\beta$-cell function. Diab Obes Metab 12, 141-148

16. Cnop, M., Foufelle, F. and Velloso, L. A. (2012) Endoplasmic reticulum stress, obesity and diabetes. Trends Mol Med 18, 59-68

17. Lowell, B. B. and Shulman, G. I. (2005) Mitochondrial dysfunction and type 2 diabetes. Science 307, 384-387

18. Prentki, M. and Madiraju, S. R. M. (2012) Glycerolipid/free fatty acid cycle and islet beta cell function in health, obesity and diabetes. Mol Cell Endocrinol 353, 88-100

19. Nolan, C. J. and Larter, C. Z. (2009) Lipotoxicity: Why do saturated fatty acids cause and monounsaturates protect against it? J Gastroenterol Hepatol 24, 703-706

20. Zhang, C.-Y., Baffy, G., Perret, P., Krauss, S., Peroni, O., Grujic, D., Hagen, T., VidalPuig, A. J., Boss, O., Kim, Y-B., Zheng, X. X., Wheeler, M. B., Shulman, G. I., Chan, C. B. and Lowell, B. B. (2001) Uncoupling protein-2 negatively regulates insulin secretion and is a major link between obesity, beta cell dysfunction, and type 2 diabetes. Cell 105, $745-755$

21. Pi, J., Bai, Y., Daniel, K. W., Liu, D., Lyght, O., Edelstein, D., Brownlee, M., Corkey, B. E. and Collins, S. (2009) Persistent oxidative stress due to absence of uncoupling protein 2 associated with impaired pancreatic beta cell function. Endocrinology 150, 30403048

22. Affourtit, C. and Brand, M. D. (2008) Uncoupling protein-2 contributes significantly to high mitochondrial proton leak in INS-1E insulinoma cells and attenuates glucosestimulated insulin secretion. Biochem J 409, 199-204.

23. Affourtit, C., Jastroch, M. and Brand, M. D. (2011) Uncoupling protein-2 attenuates glucose-stimulated insulin secretion in INS-1E insulinoma cells by lowering mitochondrial reactive oxygen species. Free Radic Biol Med 50, 609-616

24. Robson-Doucette, C. A., Sultan, S., Allister, E. M., Wikström, J. D., Koshkin, V., Bhatacharjee, A., Prentice, K. J., Sereda, S. B., Shirihai, O. S. and Wheeler, M.B. (2011) Beta cell uncoupling protein 2 regulates reactive oxygen species production, which influences both insulin and glucagon secretion. Diabetes 60, 2710-2719

25. Mulder, H. and Ling, C. (2009) Mitochondrial dysfunction in pancreatic $\beta$-cells in Type 2 Diabetes. Mol Cell Endocrinol 297, 34-40

26. Brand, M. D. and Nicholls, D. G. (2011) Assessing mitochondrial dysfunction in cells. Biochem J 435, 297-312

27. Malmgren, S., Nicholls, D. G., Taneera, J., Bacos, K., Koeck, T., Tamaddo, A., Wibom, R., Groop, L., Ling, C., Mulder, H. and Sharoyko, V. V. (2009) Tight coupling between glucose and mitochondrial metabolism in clonal beta-cells is required for robust insulin secretion. J Biol Chem 284, 32395-32404

28. Pi, J., Bai, Y., Zhang, Q., Wong, V., Floering, L. M., Daniel, K., Reece, J. M., Deeney, J. T., Andersen, M. E., Corkey, B. E. and Collins, S. (2007) Reactive oxygen species as a signal in glucose-stimulated insulin secretion. Diabetes 56, 1783-1791

29. Affourtit, C. and Brand, M. D. (2009) Measuring mitochondrial bioenergetics in INS-1E insulinoma cells. Meth Enzymol 457, 405-424

30. Merglen, A., Theander, S., Rubi, B., Chaffard, G., Wollheim, C. B. and Maechler, P. (2004) Glucose sensitivity and metabolism-secretion coupling studied during two-year continuous culture in INS-1E insulinoma cells. Endocrinology 145, 667-678

31. Huber, A. H., Kampf, J. P., Kwan, T., Zhu, B. and Kleinfeld, A. M. (2006) Fatty acidspecific fluorescent probes and their use in resolving mixtures of unbound free fatty acids in equilibrium with albumin. Biochemistry 45, 14263-14274 
32. Barlow, J., Hirschberg, V., Brand, M. D. and Affourtit, C. (2013) Measuring mitochondrial uncoupling protein-2 level and activity in insulinoma cells. Meth Enzymol 528, 257-267

33. Rutter, G. A. (2001) Nutrient-secretion coupling in the pancreatic islet beta-cell: recent advances. Mol Asp Med 22, 247-284

34. Affourtit, C. and Brand, M. D. (2006) Stronger control of ATP/ADP by proton leak in pancreatic beta cells than skeletal muscle mitochondria. Biochem J 393, 151-159

35. Barlow, J., Hirschberg, V. and Affourtit, C. (2013) On the role of mitochondria in pancreatic beta cells. In Research on Diabetes (iConcept Press) ISBN: 978-14775550-1-9

36. Robinson, K. M., Janes, M. S., Pehar, M., Monette, J. S., Ross, M. F., Hagen, T. M., Murphy, M. P. and Beckman, J. S. (2006) Selective fluorescent imaging of superoxide in vivo using ethidium-based probes. Proc Natl Acad Sci USA 103, 15038-15043

37. Newsholme, P., Morgan, D., Rebelato, E., Oliveira-Emilio, H. C., Procopio, J., Curi, R. and Carpinelli, A. (2009) Insights into the critical role of NADPH oxidase(s) in the normal and dysregulated pancreatic beta cell. Diabetologia 52, 2489-2498

38. Morgan, D., Oliveira-Emilio, H. R., Keane, D., Hirata, A. E., Santos da Rocha, M., Bordin, S., Curi, R., Newsholme, P. and Carpinelli, A. R. (2006) Glucose, palmitate and pro-inflammatory cytokines modulate production and actiyity of a phagocyte-like NADPH oxidase in rat pancreatic islets and a clonal beta cell line. Diabetologia 50, 359369

39. Hue, L. and Taegtmeyer, H. (2009) The Randle cycle revisited: a new head for an old hat. Am J Physiol: Endocrinol Met 297, E578-E591

40. Luiken, J. J. F. P., Niessen, H. E. C., Coort, S. L. M., Hoebers, N., Coumans, W. A., Schwenk, R. W., Bonen, A. and Glatz, J. F. C. (2009) Etomoxir-induced partial carnitine palmitoyltransferase-I (CPT-I) inhibition in vivo does not alter cardiac long-chain fatty acid uptake and oxidation rates. Biochem J 419, 447-455

41. Larsson, O., Deeney, J. T., Bränström, R., Berggren, P. O. and Corkey, B. E. (1996) Activation of the ATP-sensitive $\mathrm{K}^{+}$channel by long chain acyl-CoA. A role in modulation of pancreatic beta-cell glucose sensitivity. J Biol Chem 271, 10623-10626

42. Zhao, Y., Sharp, G. W. G. and Straub, S. G. (2007) The inhibitors of protein acylation, cerulenin and tunicamycin, increase voltage-dependent $\mathrm{Ca}^{2+}$ currents in the insulinsecreting INS 832/13 cell. Biochem Pharmacol 74, 273-280

43. Hoppa, M. B., Collins, S., Ramracheya, R., Hodson, L., Amisten, S., Zhang, Q., Johnson, P., Ashcroft, F. M. and Rorsman, P. (2009) Chronic palmitate exposure inhibits insulin secretion by dissociation of $\mathrm{Ca}^{2+}$ channels from secretory granules. Cell Metab 10, 455465

44. Wikstrom, J. D., Sereda, S. B., Stiles, L., Elorza, A., Allister, E. M., Neilson, A., Ferrick, D. A., Wheeler, M. B, and Shirihai, O. S. (2012) A novel high-throughput assay for islet respiration reveals uncoupling of rodent and human islets. PLoS ONE 7, e33023

45. Diakogiannaki, E., Dhayal, S., Childs, C. E., Calder, P. C., Welters, H. J. and Morgan, N. G. (2007) Mechanisms involved in the cytotoxic and cytoprotective actions of saturated versus monounsaturated long-chain fatty acids in pancreatic beta cells. J Endocrinol 194, 283-291

46. Maestre, I., Jordán, J., Calvo, S., Reig, J. A., Ceña, V., Soria, B., Prentki, M. and Roche, E. (2003) Mitochondrial dysfunction is involved in apoptosis induced by serum withdrawal and fatty acids in the beta cell line INS-1. Endocrinology 144, 335-345

47. Joseph, J., Chan, C. and Wheeler, M. (2005) UCP2 knockout mouse islets have lower consumption and faster oscillations of beta cell oxygen. Can J Diab 29, 19-26

48. Hovsepyan, M., Sargsyan, E. and Bergsten, P. (2010) Palmitate-induced changes in protein expression of insulin secreting INS-1E cells. J Proteomics 73, 1148-1155 
49. Listenberger, L. L., Han, X., Lewis, S. E., Cases, S., Farese, R. V., Ory, D. S. and Schaffer, J. E. (2003) Triglyceride accumulation protects against fatty acid-induced lipotoxicity. Proc Natl Acad Sci USA 100, 3077-3082

50. Gravena, C., Mathias, P. C. and Ashcroft, S. J. H. (2002) Acute effects of fatty acids on insulin secretion from rat and human islets of Langerhans. J Endocrinol 173, 73-80 


\section{FIGURE LEGENDS}

Figure 1 - Real-time detection of palmitate-induced mitochondrial dysfunction in intact INS-1E cells. Panel $A$ - Mitochondrial function is essential for canonical GSIS: glucose is taken up by pancreatic beta cells via an insulin-insensitive transporter (GLUT2) and broken down oxidatively, which leads to increased activity of the mitochondrial tricarboxylic acid (TCA) cycle and the mitochondrial respiratory chain (complexes I-IV), and an increased mitochondrial protonmotive force (pmf). The pmf drives ATP synthesis but may also be dissipated by mitochondrial uncoupling protein-2 (UCP2) activity. The glucose-induced rise in ATP/ADP triggers closure of ATP-sensitive potassium $\left(\mathrm{K}_{\mathrm{ATP}}\right)$ channels, depolarization of the plasma membrane $\left(\Delta \psi_{\mathrm{p}}\right), \mathrm{Ca}^{2+}$ influx and exocytosis of insulin-containing granules. Panels $B$ and $C$ - Typical traces reflecting respiration of cells exposed for $24 \mathrm{hr}$ at $11 \mathrm{mM}$ glucose to BSA (Panel B) or BSA-conjugated palmitate (Panel C). Cellular oxygen uptake was measured as described in Experimental - $28 \mathrm{mM}$ glucose (G28), $5 \mu \mathrm{g} / \mathrm{mL}$ oligomycin (OLI), and a mixture of $1 \mu \mathrm{M}$ rotenone and $2 \mu \mathrm{M}$ antimycin A (RA) were added as indicated. Data are means \pm SEM of 5 separate wells from a single XF24 plate and are expressed as a percentage of basal respiration.

Figure 2 - Palmitate exposure at high glucose dampens the glucose-sensitivity of mitochondrial respiration. Absolute basal mitochondrial and non-mitochondrial oxygen uptake (Panel $A$ : dark-grey and light-grey bars, respectively), and glucose-sensitivity of mitochondrial respiration (Panels $B$ and $C$ ) were measured in cells exposed for $24 \mathrm{hr}$ to BSAconjugated NEFAs or BSA alone at $11 \mathrm{mM}$ glucose (Panels $A$ and $B$ ) or $4 \mathrm{mM}$ glucose (Panel $C$ ). Data are means \pm SEM of 3-5 independent experiments that each involved 3-4 replicates per treatment. Statistical significance of mean differences for cells subjected to 28 $\mathrm{mM}$ glucose was tested by 2 -way ANOVA. Panel $B$ - palmitate versus BSA: $P<0.001$; palmitate + palmitoleate versus BSA: $P<0.05$; palmitate versus palmitoleate: $P<0.01$. Panel $C$ - not significant. Panel $B$ versus Panel $C$ - BSA: not significant; palmitate: $P<$ 0.00001; palmitoleate: not significant; palmitate + palmitoleate: $P<0.01$. Closed circles $=$ $\mathrm{BSA}$; closed triangles $=$ palmitate open triangles $=$ palmitoleate open squares $=$ palmitate + palmitoleate.

Figure 3 - Palmitate exposure at high glucose attenuates mitochondrial coupling efficiency. Coupling efficiency of oxidative phosphorylation - assayed at 4-28 mM glucose was calculated as the percentage glucose-stimulated mitochondrial respiration sensitive to oligomycin in cells that had been exposed for $24 \mathrm{hr}$ to BSA-conjugated NEFAs or BSA alone at $11 \mathrm{mM}$ glucose $($ Panel $A)$ or $4 \mathrm{mM}$ glucose (Panel B). Data are means \pm SEM from 3-5 independent experiments that each involved 3-4 replicates per treatment. Statistical significance of mean differences for cells subjected to $28 \mathrm{mM}$ glucose was tested by 2-way ANOVA. Panel $A$ - palmitate versus BSA: $P<0.05$; palmitate + palmitoleate versus BSA: $P$ $<0.05$; palmitate versus palmitoleate: $P<0.01$. Panel $B-$ not significant. Panel $A$ versus Panel $B$ - BSA: not significant; palmitate: $P<0.01$; palmitoleate: not significant; palmitate + palmitoleate: $P<0.05$. Closed circles $=\mathrm{BSA}$; closed triangles $=$ palmitate; open triangles $=$ palmitoleate; open squares $=$ palmitate + palmitoleate.

Figure 4 - Palmitate exposure at high glucose decreases ADP phosphorylation-coupled, glucose-stimulated mitochondrial respiration but does not affect proton leak. Absolute total mitochondrial respiratory activity at $28 \mathrm{mM}$ glucose (Total), and absolute oligomycinsensitive (Phosphorylation) and oligomycin-resistant (Leak) activities were calculated from cell number-normalised basal mitochondrial respiration (Fig. 2A), the sensitivity of basal mitochondrial respiration to $28 \mathrm{mM}$ glucose (Fig. 2B), and the coupling efficiency of 
oxidative phosphosphorylation at $28 \mathrm{mM}$ glucose (Fig. 3A). Data are means \pm SEM of 4 separate experiments that each involved 3-4 replicates per treatment. Statistical significance of differences between groups was tested by 1-way ANOVA: * differs from 'palmitate' and 'palmitate + palmitoleate' conditions $(P<0.05)$; $* * *$ differs from 'palmitate' and 'palmitate + palmitoleate' conditions $(P<0.001)$. Dark-grey bars = BSA; open bars = palmitate; lightgrey bars $=$ palmitoleate; black bars $=$ palmitate + palmitoleate .

Figure 5 - Palmitate exposure at high glucose increases ROS. Mitochondrial superoxide was estimated from MitoSOX oxidation in INS-1E cells exposed for $24 \mathrm{hr}$ to BSAconjugated NEFAs or BSA alone at $11 \mathrm{mM}($ Panel $A)$ or $4 \mathrm{mM}($ Panel B) glucose. Panels $A$ and $B$ : MitoSOX $(5 \mu \mathrm{M})$ was injected during the assay as indicated by the arrow and fluorescence was recorded at 28 -sec intervals - for clarity, only a selection of measurements is shown. Relative fluorescence units (RFU) were corrected for low background fluorescence observed in cell-free controls and were normalised to cell number using averaged viability data shown in Fig. 7. Closed triangles $=$ BSA; closed circles $=$ palmitate; open diamonds $=$ palmitoleate; open squares $=$ palmitate + palmitoleate. Panel $C$ : MitoSOX oxidation rates were calculated from the slopes of the progress curves shown in Panels $A$ and $B$ (dark-grey and light-grey bars $=$ NEFA-exposure at 11 and $4 \mathrm{mM}$ glucose, respectively). Except for the first 4 measurements, all data recorded following MitoSOX addition were included in these calculations. Data are means \pm SEM of 3-6 independent experiments that involved 7-8 replicates per treatment. Statistical significance of mean differences was tested by 2-way ANOVA: * differs from the equivalent palmitate condition $(\mathrm{P}<0.05)$; ** differs from the equivalent palmitate condition $(\mathrm{P}<0.01)$.

Figure 6 - Palmitate exposure at high glucose impairs glucose-stimulated and KClinduced insulin secretion. Insulin secretion ( $\mathrm{ng} / \mathrm{well} / 30 \mathrm{~min}$ ) was measured in control cells grown in RPMI (Panel $A$ ) and in cells exposed for $24 \mathrm{hr}$ to BSA-conjugated NEFAs or BSA alone at $11 \mathrm{mM}$ glucose (Panels $B$ and $C$ ) or $4 \mathrm{mM}$ glucose (Panel D). Following glucose starvation, cells were subjected to $0-28 \mathrm{mM}$ glucose (Panel $A$ : G0, G4, G11, G28) or to 4 $\mathrm{mM}$ glucose and $50 \mathrm{mM} \mathrm{KCl}$ (Panel $A$ : $\mathrm{KCl}$ ). GSIS was expressed as the G28/G0 insulin secretion ratio (Panels $B$ and $D$ ) and $\mathrm{KCl}$-induced insulin secretion was normalised to insulin secretion at $4 \mathrm{mM}$ glucose (Pane/ $C$ ). Data are means \pm SEM of 4-6 independent experiments that involved 4-5 replicates per treatment. Statistical significance of mean differences was tested by 1-way ANOVA: * differs from G0 condition (Panel A) or BSA condition (Panel B) $(P<0.05)$.

Figure 7 - Palmitate exposure causes cell viability loss at high glucose. Cell viability was determined by measuring the total metabolic activity within individual culture plate wells (see Experimental) that contained cells exposed for $24 \mathrm{hr}$ to BSA-conjugated NEFAs or BSA alone at $11 \mathrm{mM}$ glucose (Panel A) or $4 \mathrm{mM}$ glucose (Panel B). To quantify cell viability, total metabolic activity in each well was expressed as a percentage of the activity exhibited by wells that contained cells grown in fully supplemented RPMI - it was confirmed by light microscopy that these RPMI wells showed no signs of cell loss. Cell viability percentages were then normalised to the BSA controls. BSA alone causes about $5 \%$ and $20 \%$ cell loss when administered in serum-free RPMI at 11 and $4 \mathrm{mM}$ glucose, respectively. Data are means \pm SEM of 5-6 independent experiments that each involved 3-4 replicates per treatment. Statistical significance of mean differences was tested by 2-way ANOVA: ** differs from BSA and palmitoleate conditions $(P<0.01)$.

Figure 8 - Mitochondrial toxicity of palmitate exposure emerges at low glucose when NEFA oxidation is inhibited. The glucose-sensitivity of mitochondrial respiration (Panels $A$ 
and $B$ ) and coupling efficiency of oxidative phosphorylation (Panel $C$ ) were measured in cells exposed for $24 \mathrm{hr}$ to BSA-conjugated palmitate (grey bars) or BSA alone (dark-grey bars) at $11 \mathrm{mM}$ glucose (G11), at $4 \mathrm{mM}$ glucose (G4), or at $4 \mathrm{mM}$ glucose with $50 \mu \mathrm{M}$ etomoxir (G4+ETO). Mitochondrial respiration stimulated by $28 \mathrm{mM}$ glucose was either normalised to basal respiration (Panel $A$ ) or to the respective glucose-stimulated BSA conditions (Panel B). Coupling efficiencies at $28 \mathrm{mM}$ glucose were calculated as described in Experimental. Data are means \pm SEM of 4-5 independent experiments that each involved 3-4 replicates per treatment. Statistical significance of mean differences was tested by 2 -way ANOVA: * differs from equivalent palmitate condition $(P<0.05) ; * *$ differs from equivalent G4 condition $(P<0.05)$.

Figure 9 - A metabolic balance model of glucolipotoxicity. NEFA and glucose exposure phenotypes are the net result of deleterious and beneficial NEFA-induced processes. See text for further details. 
Figure 1
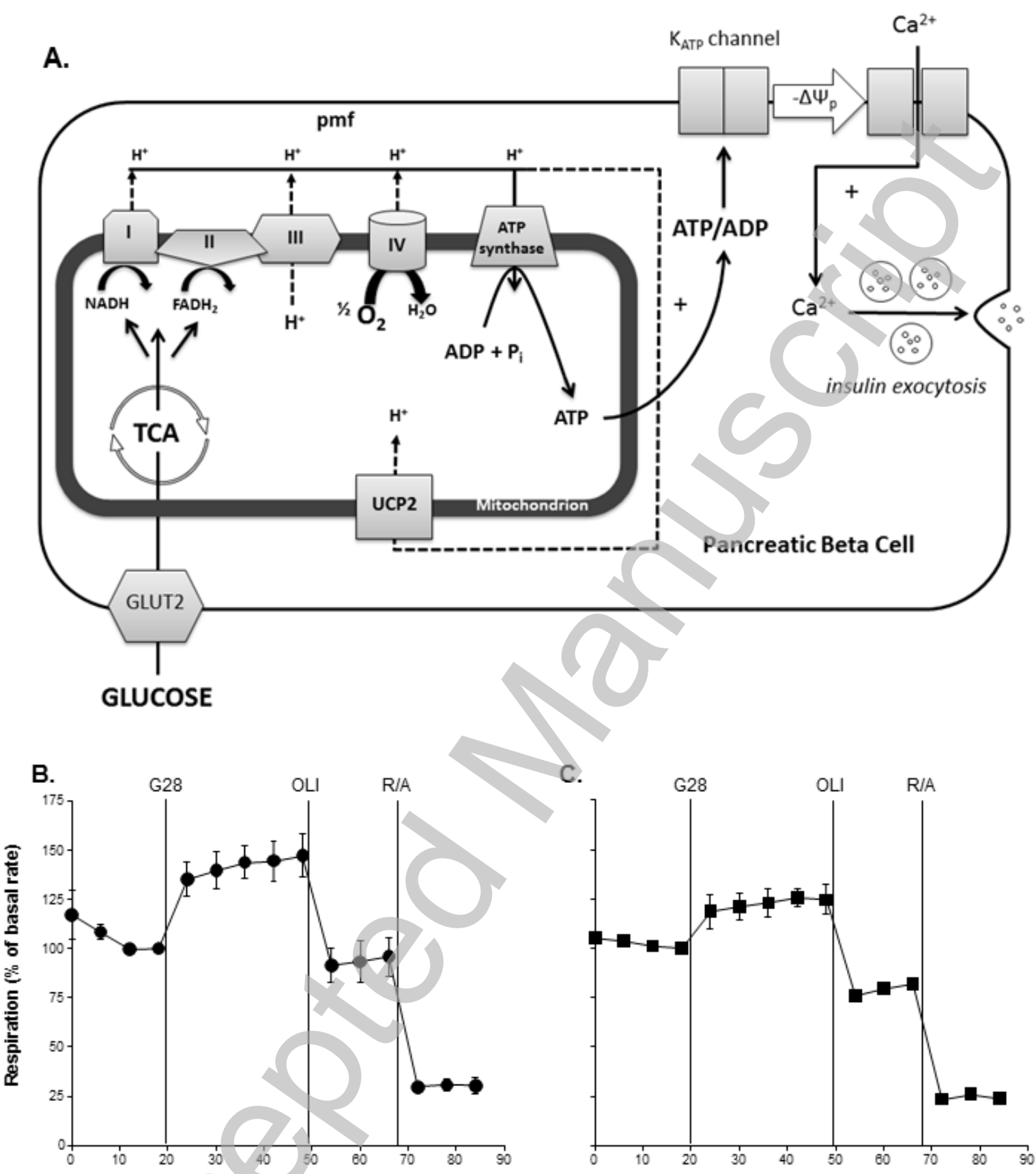

C.

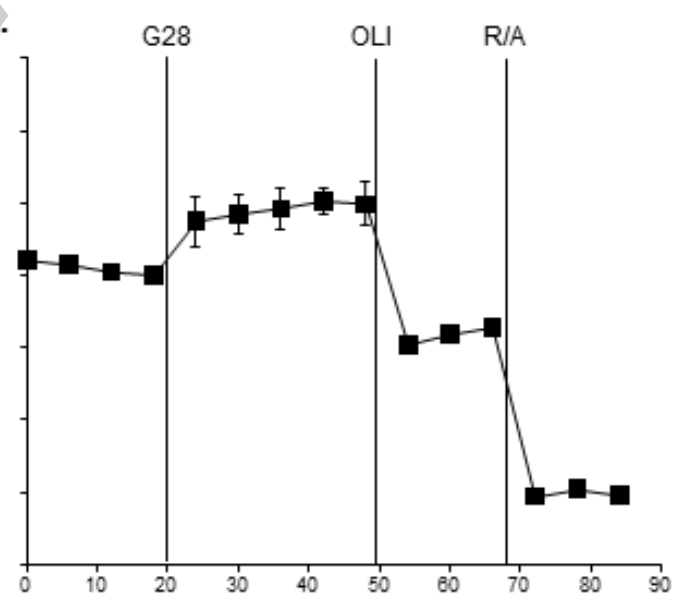

Time (min) 


\section{Figure 2}

A.
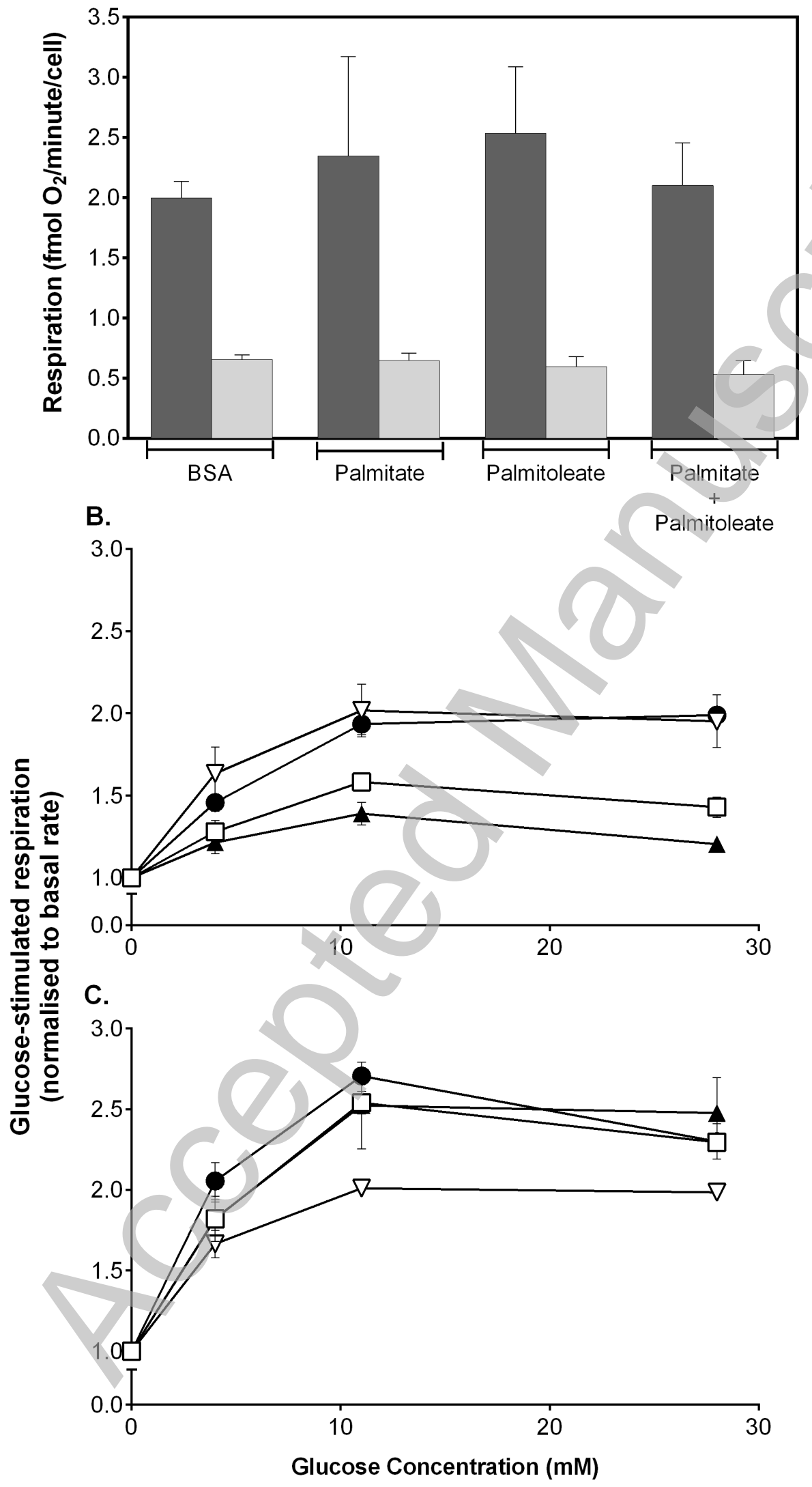

19

Licenced copy. Copying is not permitted, except with prior permission and as allowed by law. (c) 2013 The Authors Journal compilation (c) 2013 Biochemical Society 
Figure 3

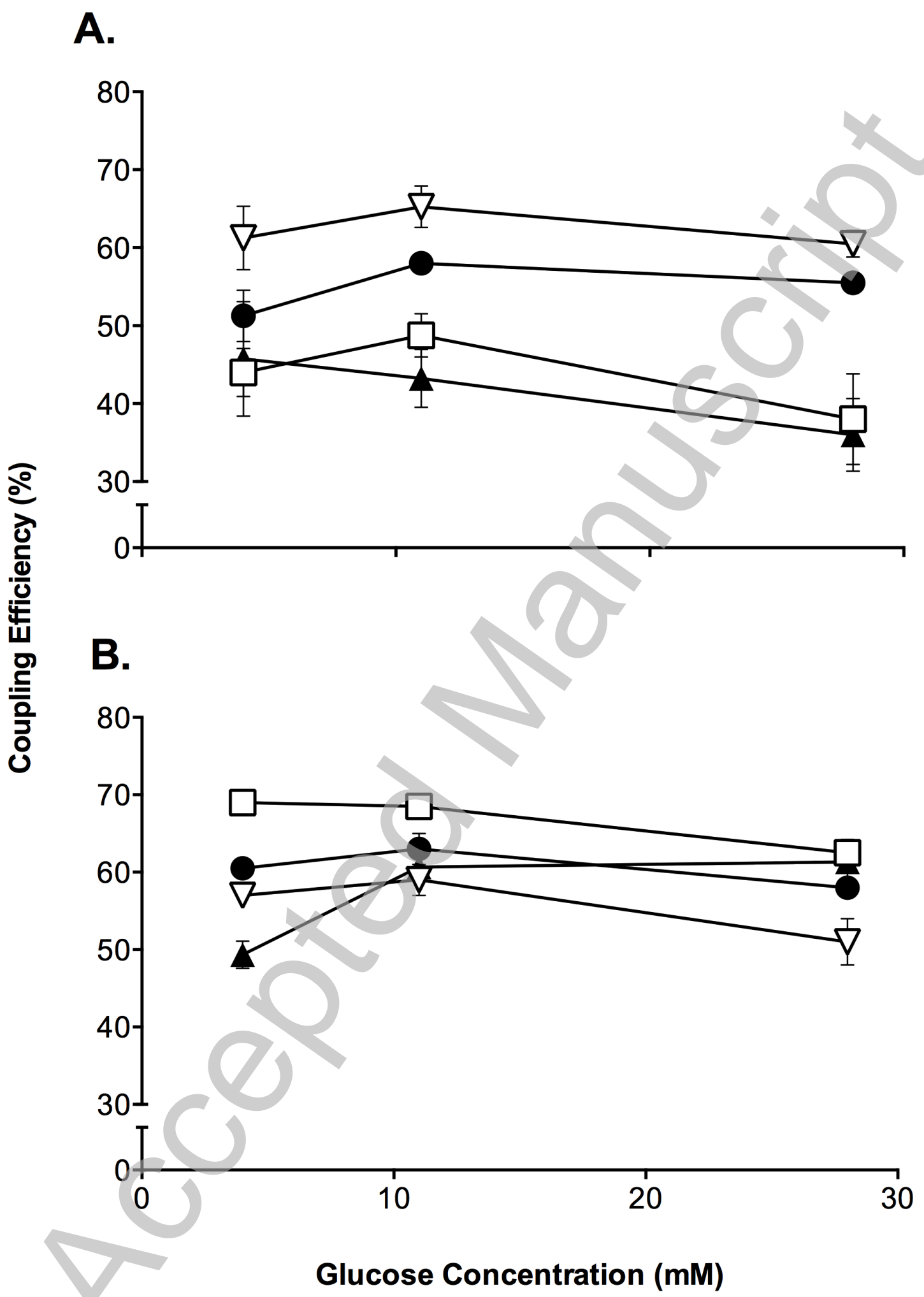


Figure 4

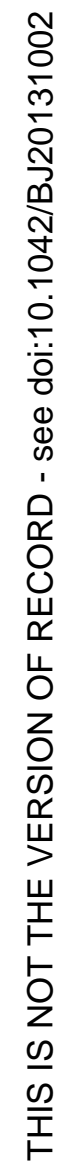

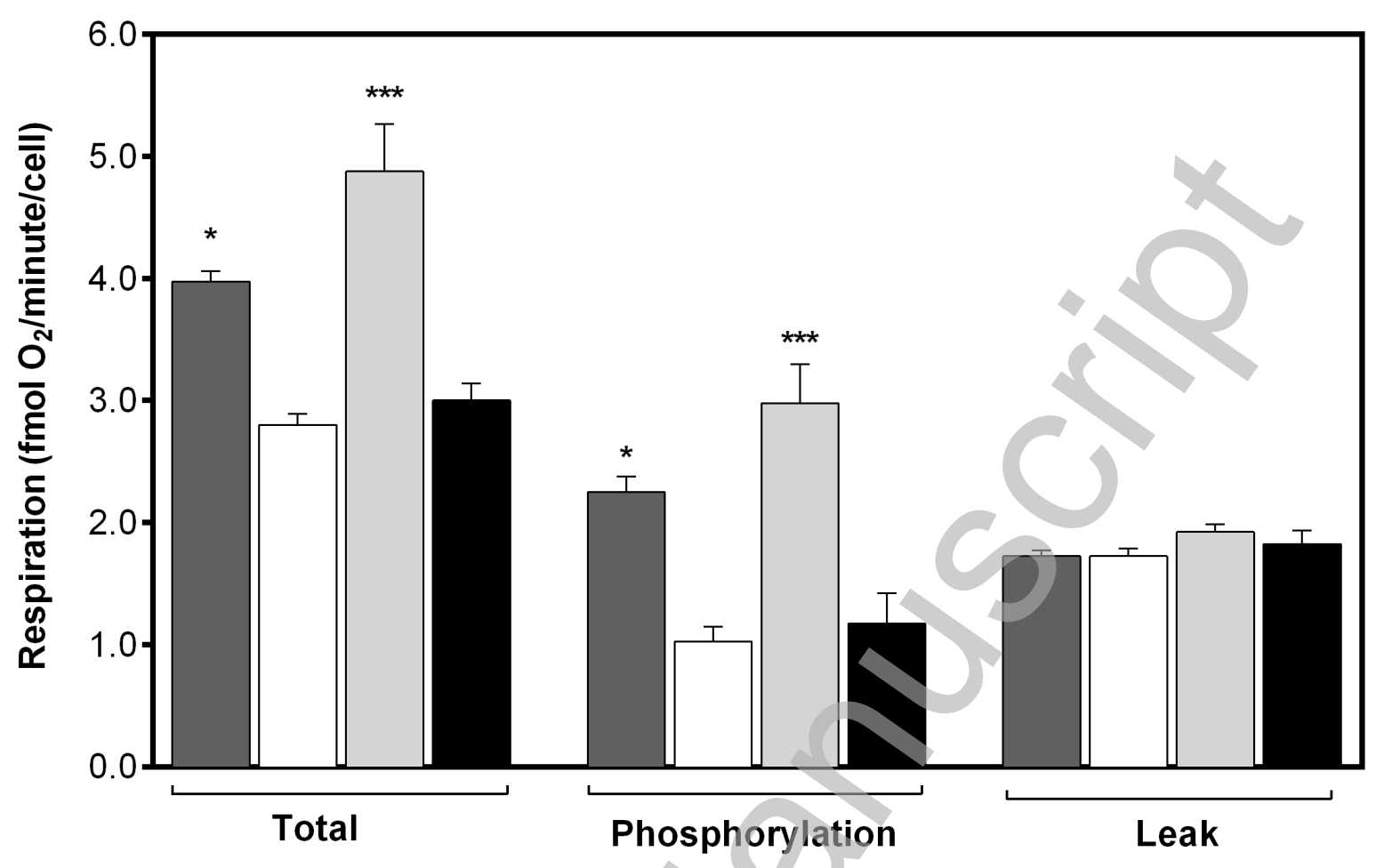




\section{Figure 5}
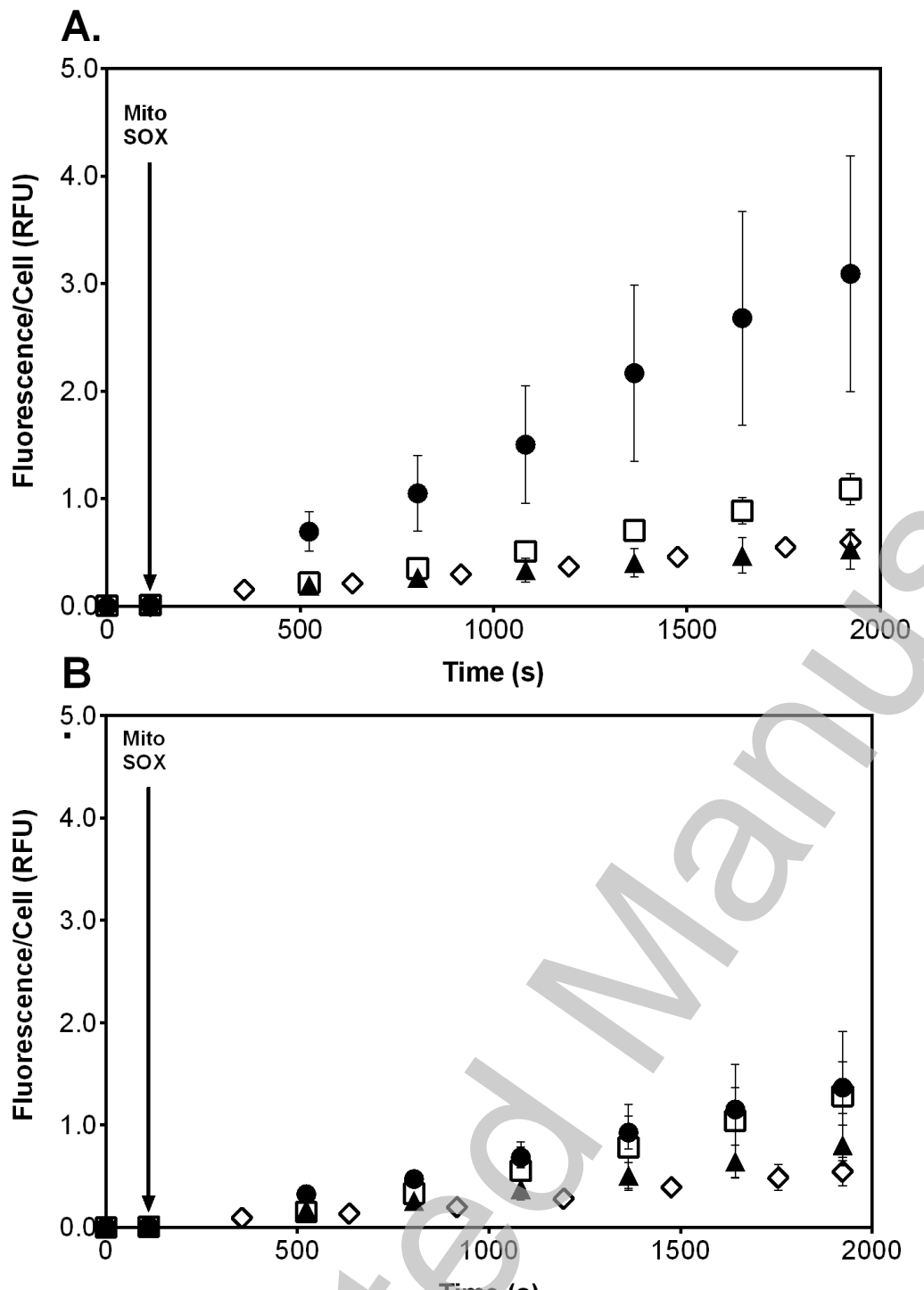

C.

Time (s)

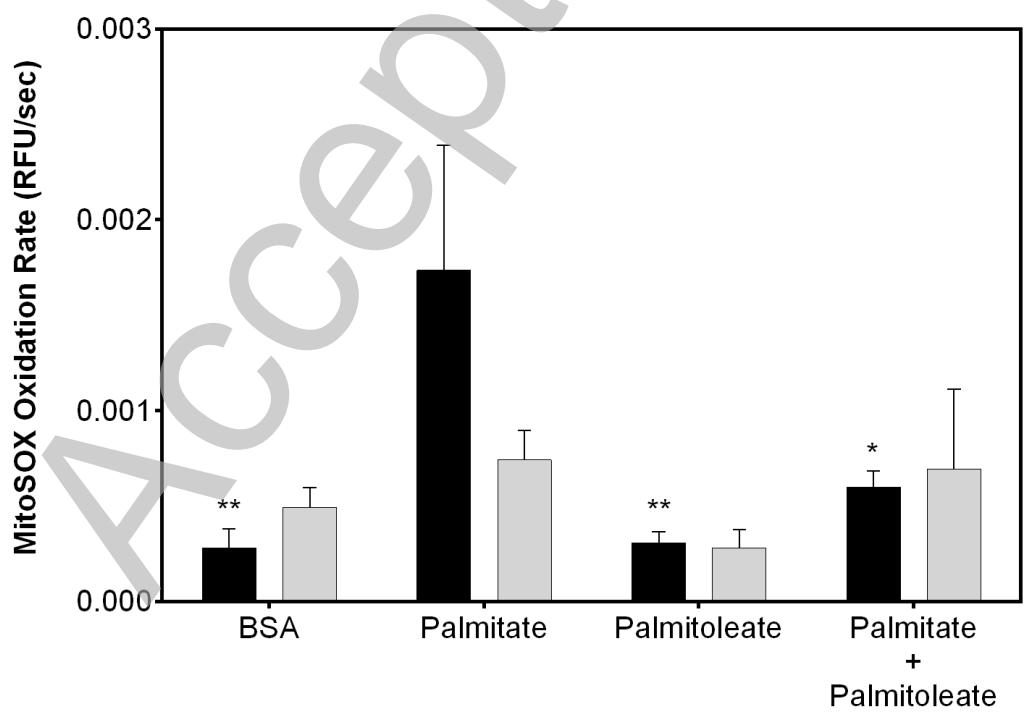




\section{Figure 6}

A.

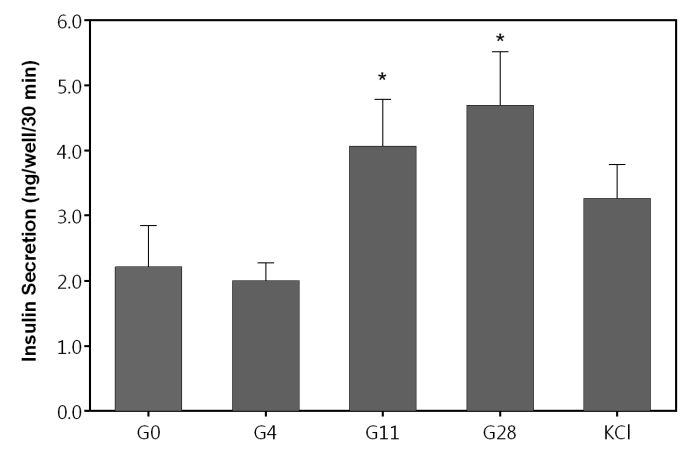

c.

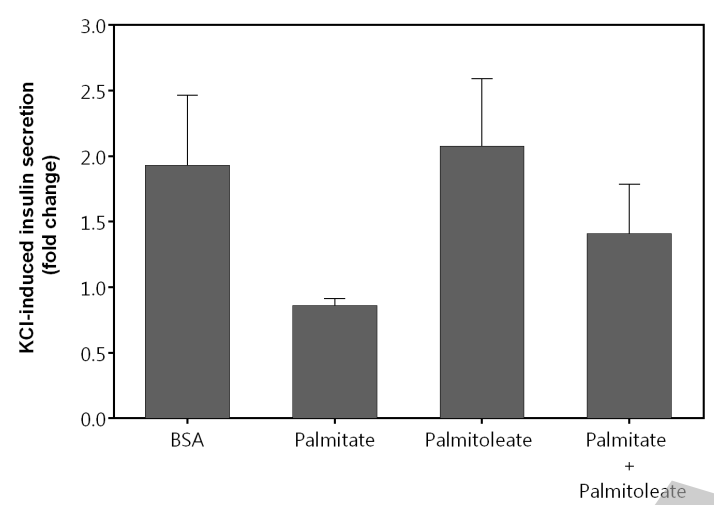

B.

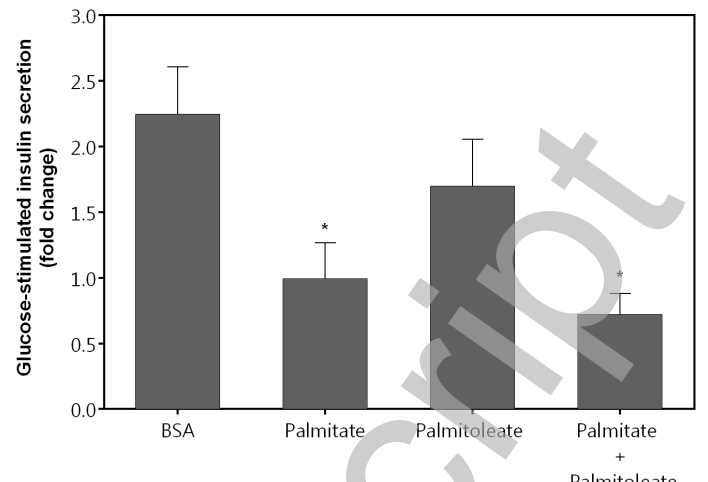

Palmitoleate

D.

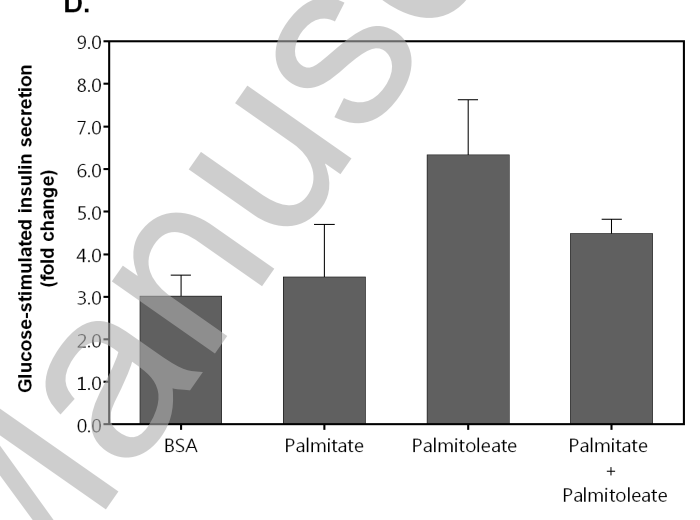

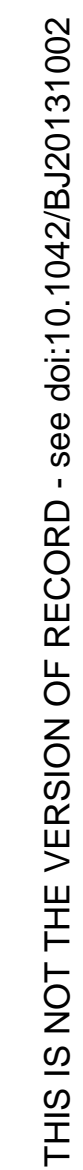




\section{Figure 7}

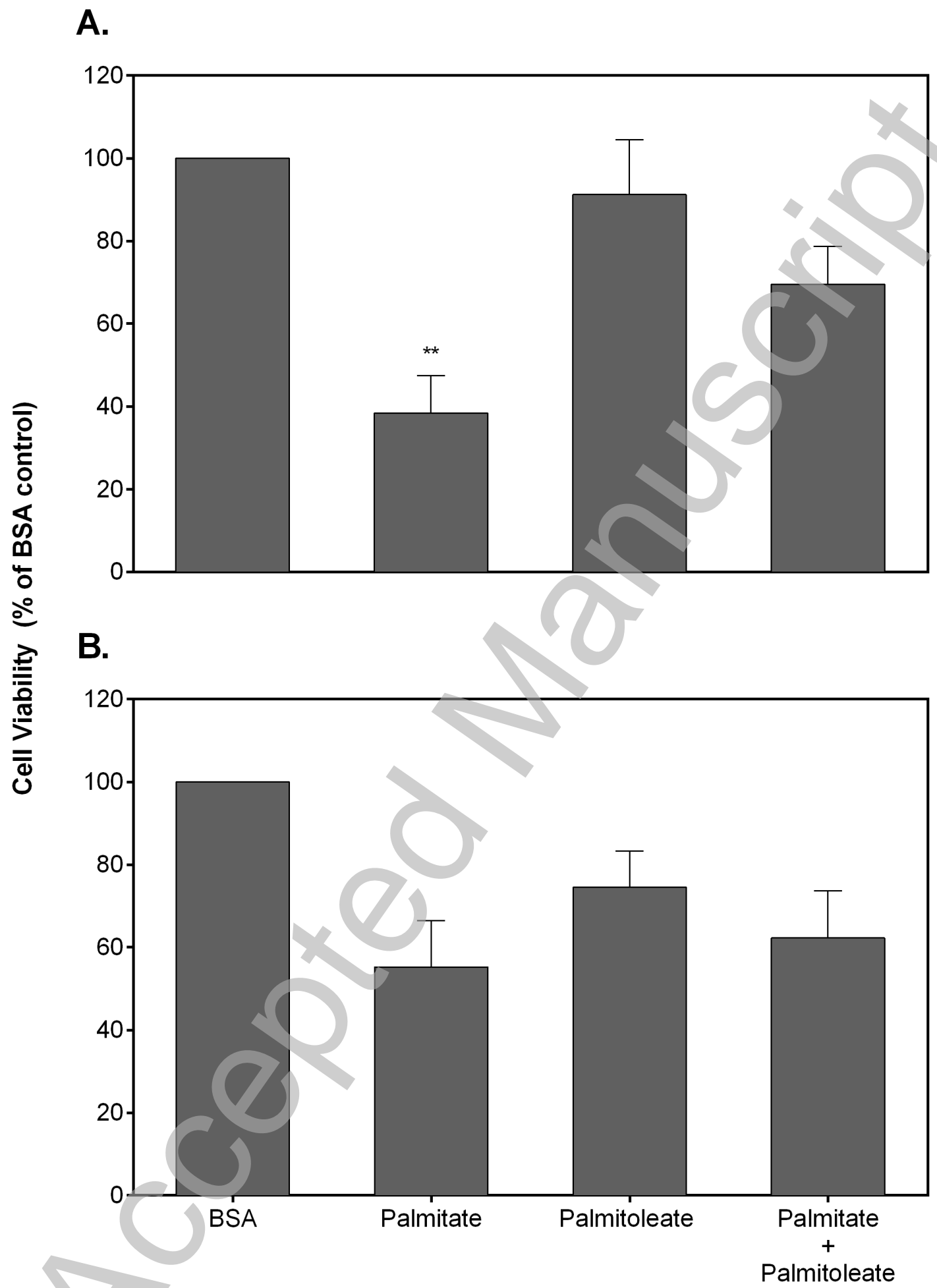




\section{Figure 8}

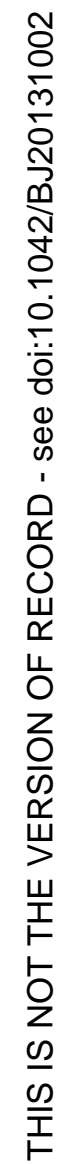

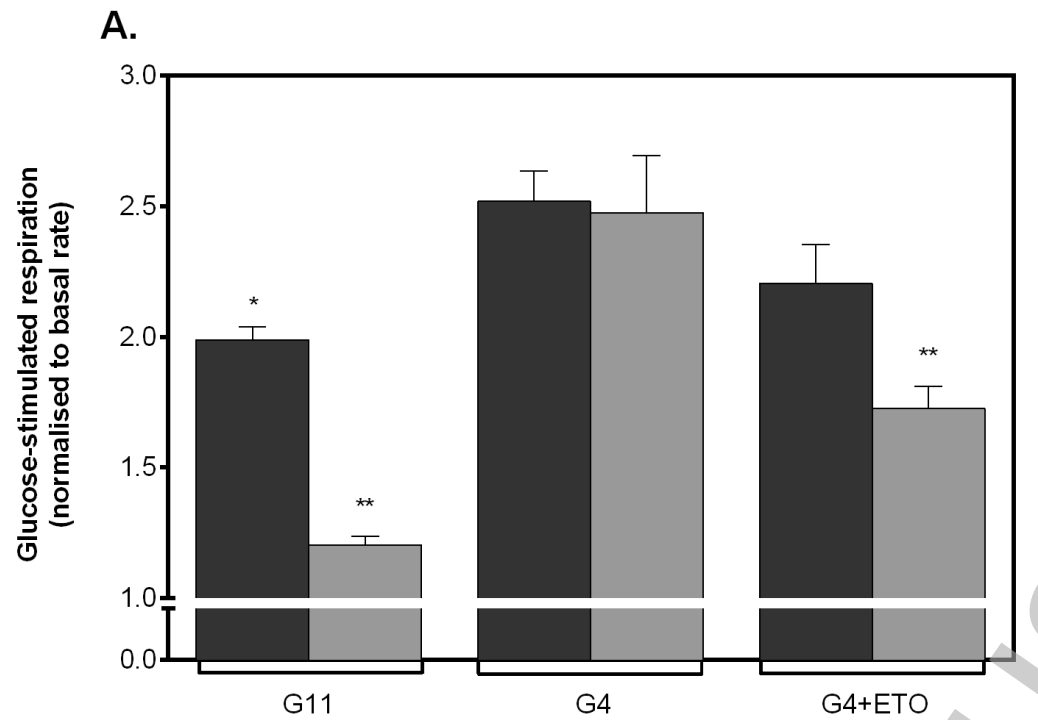

B.

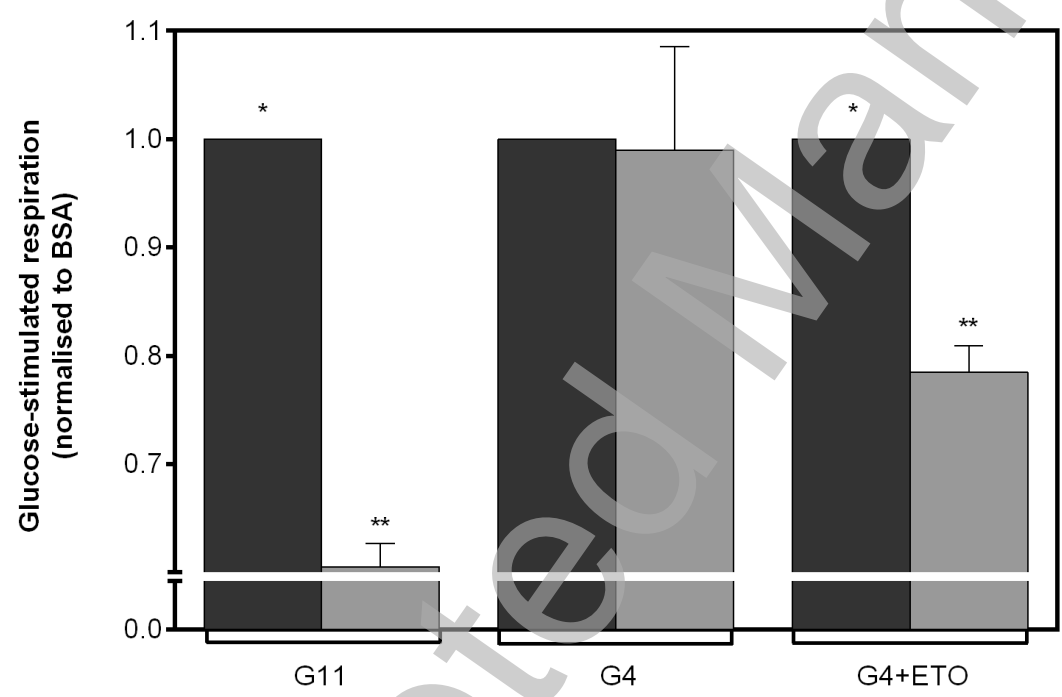

C.

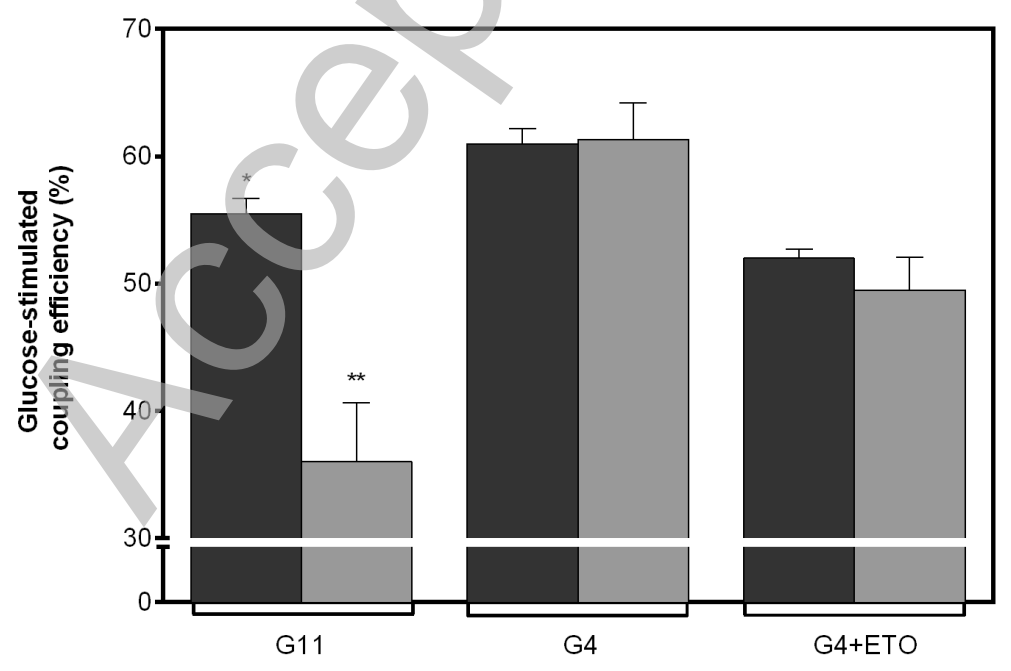


Figure 9

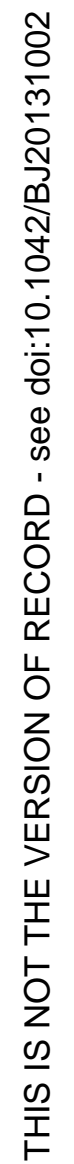

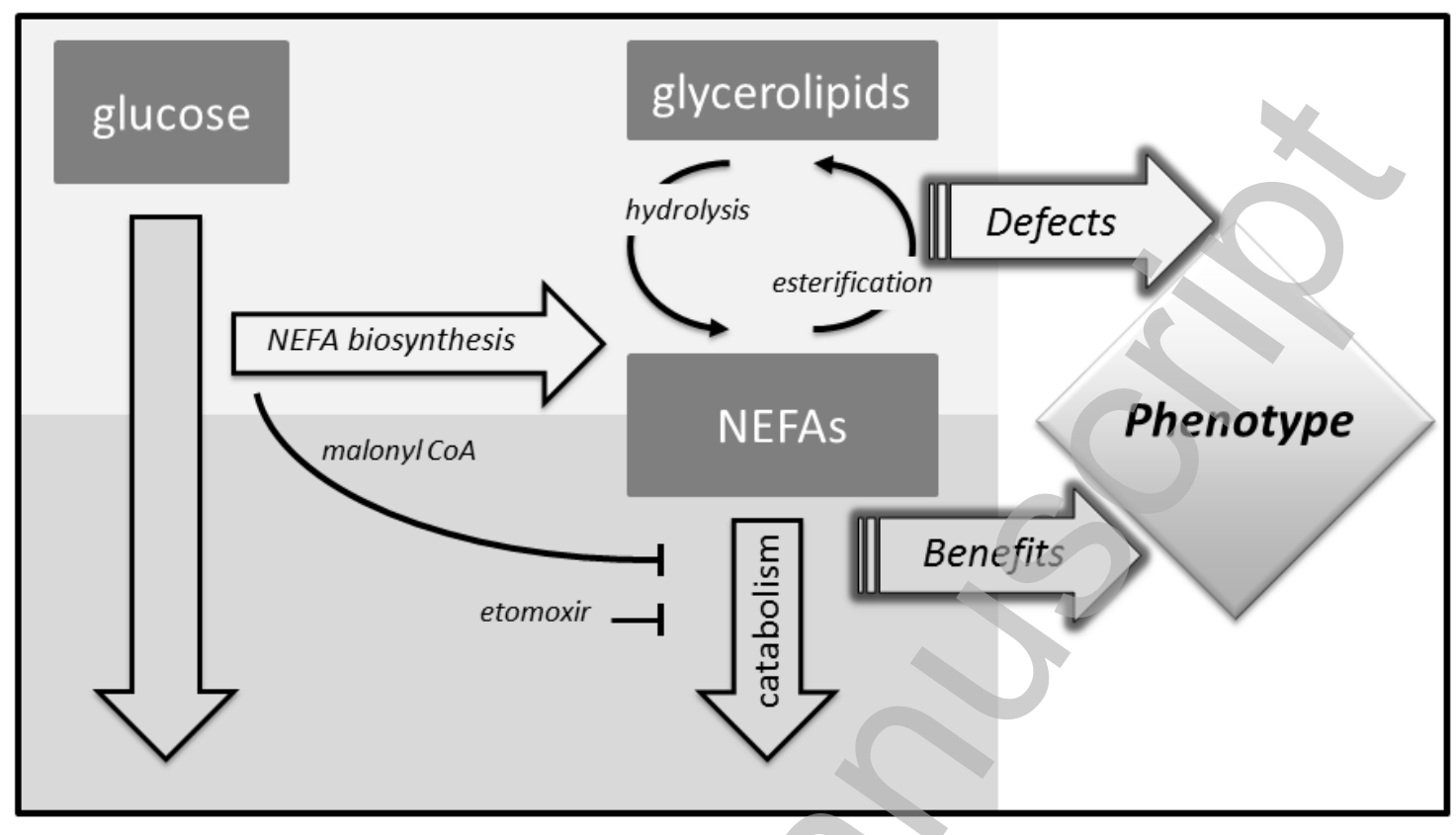

